\title{
The spatial impact of language policies on the marginal bids for English education in Hong Kong
}

\section{Abstract}

In 1997 the government of Hong Kong reformed its policy on the language medium for teaching at the secondary-school level and removed schools’ right to choose their own medium. Among the 404 public and “aided” secondary schools in Hong Kong, the government allowed only 100 to use English as the medium for teaching and required the remaining 304 to use the native language, Chinese. The authors assess the spatial impact of the policy reform and estimate the bid function for English-language schools. The results show that the 1997 policy reform shifted parental preferences from public to private education and increased the marginal bid for proximity to private English schools by 2 percent. Following the reform, homeowners were willing to pay, on average, HK $\$ 8,400$ for each additional 100 metres closer to a private English school.

\section{Introduction}

The present study estimates and applies the bid function to assess the spatial impact of the 1997 education policy reform in Hong Kong. It examines changes in the marginal bid—-the marginal willingness to pay or the implicit demand-for proximity to those primary schools that were linked to English secondary schools after the government of the Hong Kong Special Administrative Region (SAR) reformed education policy. Prior to 1997, secondary schools were free to choose their language of instruction. In 1997 the SAR government abolished autonomy and restricted to only 100 secondary schools the use of English as the medium of instruction, forcing the remaining 304 schools to teach in the mother tongue, Chinese. Although the policy reform targeted secondary schools only, it directly influenced primary schools because pupil allocation to secondary schools was dependent on the school district in which the primary school was located.

The present study focuses on primary schools in Hong Kong before and after the policy change. The main hypothesis is that the 1997 policy reform may have increased the demand for 
private education, especially with regard to those private primary schools that were linked to English secondary schools.

The effect of school quality on house prices has long been generating interest in the housing literature. Almost all previous studies agree that good schools are an amenity that is capitalized into house prices (Barrow and Rouse, 2004; Black, 1999; Bogard and Cromwell, 2000; Brasington, 1999, 2000; Cheshire and Sheppard, 2004; Colwell and Guntermann, 1984; Haurin and Brasington, 1996; Hilber and Mayer, 2004; Jud and Watts, 1981; Weimer and Wolkoff, 2001). Most studies have focused on quality of inputs, such as teacher-pupil ratio (Angrist and Lavy, 1999) and state aids (Barrow and Rouse, 2004), or outputs, such as test scores (Friesen and Krauth, 2007; Weimer and Wolkoff, 2001) and wages (Card, 1995; Card and Krueger, 1996). Almost no studies have considered schools' language of instruction. This omission stems from the fact that all the research to date has been conducted in a context where English is the mother tongue and where the choice of language of instruction is therefore unnecessary.

In nations where English is not the mother tongue, schools often face the dilemma of which medium of instruction to adopt. Hong Kong is a case in point. On the one hand, proficiency in English is perceived as offering a person more career choices and better economic outcomes. On the other hand, instruction in the mother tongue may provide a more conducive environment for effective learning. This dilemma has been the subject of policy debate since 1842, when Hong Kong was colonized. The colonial government adopted a hands-off approach, allowing secondary schools to choose their medium of instruction. In 1997 Hong Kong’s sovereignty was returned to the Chinese government and the Hong Kong SAR government was established. The SAR government revoked the colonial approach and regulated the medium of instruction at the secondary-school level.

Since the 1997 policy reform, there has been a surge in the number of education studies on language choice (Berry and McNeil, 2005; Dimmock and Walker, 1997; Evans, 2000, 2002; Ho and Ho, 2004); however, the number of studies that focus on the spatial impact of the reform remains 
negligible. The reform encouraged parents to choose the language of learning for their children by moving close to the primary schools that were linked to English secondary schools and bidding up the value of properties located close to these primary schools. The goal of the present study is to assess the value of an English school and describe the spatial pattern of the change in property values around English schools.

Two independent random samples of transacted properties are drawn from the database of one of the largest local realtors in Hong Kong. The first sample consists of apartments that were sold in 1996, prior to the policy reform, and the second sample comprises apartments that were sold in 2001, four years after the reform. The property price data are geocoded against the street network file; they are then matched up with the school profile data and the census socioeconomic profile of neighbourhoods. The study first estimates the hedonic regression (the market price) and then the bid function (the demand side) for primary schools that are linked to English secondary schools, controlling for neighbourhood and school characteristics. The results show that the 1996-2001 increase in the marginal bid for each 100 metres closer to a primary school approximates HK \$8,400 (approximately US \$1,100) if the primary school is private and is linked to an English secondary school, compared to the 1996 marginal bid for an average primary school. (Unless otherwise stated, all dollar values are based on the 2001 Hong Kong dollar. Note that HK \$7.8 is fixed at an exchange rate of US \$1.0.)

This paper contributes to the urban housing literature, in at least three ways. First, the study relates a region's language policy to its spatial outcome in the housing market. It reveals the important role that geography plays in assessing urban social policies. It shows that policies that are intended as aspatial may entail spatial influences, particularly through the housing market. Second, the policy reform in Hong Kong provides an interesting context for studying language issues, property prices and bids. While there is an increasing number of housing studies that focus on school quality (Hilber and Mayer, 2004) and pupils’ education experience (Ledwith, 2009; Sykes and 
Kuyper, 2009), none of the existing studies focuses on similar language issues as those experienced in Hong Kong during the political transition from the British to the Chinese government. ${ }^{1}$ Most studies that examine language and policy deal with immigrants and assimilation processes. Third, the 1997 reform presents itself as a natural experiment that allows one to estimate the household bid for school quality and the provision of an English-language education.

The remainder of the paper is organized as follows. The next section briefly reviews the education system and language policies of Hong Kong. This is followed by a discussion of the analytical framework, estimating strategies, and data and variables. Then the results are summarized and a brief conclusion is presented.

\section{Background}

\subsection{Overview}

Primary and secondary schools in Hong Kong can be categorized in one of three groups, based on their source of funding: private, public or government-aided. Private schools are funded by private sources. Most private schools in Hong Kong are “international schools,” whose curriculum follows that of their home country. ${ }^{2}$ Public schools are wholly funded and operated by the Hong Kong SAR government. Government-aided schools (aided schools, for short) receive subsidies from the government while obtaining financial assistance from other sponsors, including religious groups, ${ }^{3}$

\footnotetext{
${ }^{1}$ Quebec, Canada, encounters a similar language controversy in its school system; however, to the authors' understanding, none of the existing housing studies on Quebec's language policy and education system attempts to estimate Anglophones' willingness to pay for English education.

${ }^{2}$ The Canadian International School, the California School and the German Swiss International Schools are just a few examples.

${ }^{3}$ The main denominational groups that fund schools in Hong Kong are the Anglicans, Catholics and Buddhists.
} 
charitable organizations, ${ }^{4}$ alumni of various educational institutions, ${ }^{5}$ and trade guilds. ${ }^{6}$ Both public and aided schools follow the curriculum set by the SAR government's Education Board. ${ }^{7}$

One particular group of schools is operated by the English School Foundation (ESF). ESF schools are aided schools, serving mainly the children of expatriates. Unlike other aided schools, however, ESF schools are allowed to charge incidental and tuition fees to support facilities in addition to the instituted curriculum. Because ESF schools differ from most other aided schools, both financially and operationally, they are often perceived by Hong Kong residents as private.

In terms of placements, public and aided schools enrol close to 90 percent of all primary school pupils, while private schools enrol 10 percent (Table 1). From the 1960s to the 1990s, the number of placements in public primary and secondary schools fell short of demand. As a policy response, the government purchased places from aided and private schools under the Bought Place Scheme, which in 1991 was replaced by the Direct Subsidy Scheme (DSS). Schools funded under the DSS were entitled to receive, from the government, the average unit cost per enrolment, and could charge a tuition fee that was no more than one third of the unit cost. They were given the autonomy to design their own curriculum, set admission requirements and formulate internal policies. Due to a low cap on tuition fees, however, DSS-funded schools were not popular. Appendix 1 provides a brief overview of the secondary school allocation scheme in Hong Kong.

\subsection{Language policy and the policy reform}

\footnotetext{
${ }^{4}$ One of the largest charitable organizations that sponsor primary and secondary schools in Hong Kong is Po Leung Kuk.

5 An example would be Queen's College Old Boys' Association.

${ }^{6}$ For example, the Cotton Spinners Association and the Fisheries Joint Association.

${ }^{7}$ Education Department was the agency overlooking education and related matters in Hong Kong under the colonial government; it was renamed as Education Bureau under the SAR government. Education Board, however, is the advisory board to the government.
} 
The language of instruction has been a controversy in Hong Kong ever since colonization in $1842 .^{8}$

By the early 1940s the controversy had led to an education system split into two streams: the English stream, which used English as the medium of instruction (EMI), and the Chinese stream, which used Chinese (CMI). Schools in the English stream (English schools, for short) grew at the expense of the Chinese stream (Chinese schools), particularly at the secondary level. ${ }^{9}$ Despite the demand for English schools, educators were concerned about the quality of education because, in some English secondary schools, pupils’ basic English-language skills were questionable, let alone their ability to learn other subjects with English as the language of instruction. ${ }^{10}$

In 1990 the government changed the policy direction. The government would guide public and aided secondary schools in choosing their medium of instruction and set a timeline for schools to switch to the Chinese language. According to the timeline, in 1994-97 the government would start advising schools on their appropriate medium of instruction, based on their pupils’ academic

\footnotetext{
${ }^{8}$ The first sign of conflict occurred in the mid-1870s when Governor J.P. Hennessy attempted to impose the use of English as the medium of instruction on all schools. This move was opposed by F. Stewart, the Inspector of Government Schools, who was of the view that schools over-emphasized English at the expense of the native language, Chinese. Discussions on the choice of language led to the 1878 Education Conference, which resulted in the decision to adopt English as the medium of instruction at Central School, which had been the first government-run school, opened in 1862. The debate continued into the 1900s. The year 1911 saw the opening of the University of Hong Kong, an Englishlanguage institution. During the next three decades enthusiasm for vernacular education increased as the number of migrants and refugees from mainland China rose. The heightened enthusiasm not only led to a rise in the number of private vernacular schools but also served to turn educators' attention towards restructuring Hong Kong's education system to meet people's language needs. In 1935 Edmund Burney, a British Inspector of Schools, proposed that Hong Kong's colonial education be restructured to support mother-tongue teaching. This proposal was strongly opposed by the leading aided schools and by parents and was eventually dropped. By the 1950s enrolment in English and Chinese secondary schools was almost balanced. In the mid-1960s the government opened the Chinese University of Hong Kong, which provided Chinese-language tertiary education for pupils graduating from Chinese secondary schools.

${ }^{9}$ By the mid-1980s the vast majority of children in Hong Kong were enrolled in a vernacular school at the primary level but in an English school at the secondary level. English secondary schools flourished, for at least two reasons. First, the colonial government was instrumental in creating an environment that enhanced the use of English by promoting English as the official language. Second, Hong Kong's rapid economic development as an entrepôt during the 1970s created a demand for workers who could communicate in English. In light of the high correlation among economic growth, job prospects and proficiency in English, parents perceived English schools as superior institutions and as vehicles for upward social mobility.

${ }^{10}$ For example, the 1973 Report of the Board of Education on the Expansion of Secondary School Education in Hong Kong in the Next Decade (the Education Green Paper) recommended use of the mother tongue as the medium of instruction (Hong Kong Board of Education, 1973). The subsequent White Paper on Education Policy (Hong Kong Board of Education, 1974) did not adopt the recommendations contained in the Green Paper and continued to base the decision on parental demand and economic factors. In 1982 a panel of overseas educators conducted a comprehensive review of education in Hong Kong and recommended (yet again) the use of the mother tongue to deliver education. The subsequent Education Commission Report Nos. 1 and 2 (Education Commission 1984, 1986) largely supported the status quo and left the decision regarding medium of instruction up to the schools.
} 
performance, and by 1998 schools would be "firmly guided" by the government in their choice of

medium. The timeline received little attention by the media and by the schools themselves until 1997, when the SAR government sternly executed its policy reform favouring mother-tongue teaching (Education Commission, 2005). In 1997 the government eventually publicly announced the education reform and stipulated that each secondary school had to use Chinese (either Cantonese or Putonghua) as the medium of instruction unless it applied to the Education Board for an exemption and satisfied a set of criteria. ${ }^{11,12}$ Non-compliant schools were threatened with sanctions (Hong Kong Board of Education, 1997a, 2002) ${ }^{13}$ Despite the fact that the policy reform started its planning in the early 1990s, it was not until 1997 that the policy announcement shocked the schools and the parents.

\subsection{Immediate reactions by stakeholders}

The 1997 policy reform attracted strong opposition from various stakeholders (Chan, 2002): 11 The policy reform was published in the document Guidance on Secondary Schools' Medium of Instruction. (Hong
Kong Board of Education, 1997b).

12 The criteria were:

1. No less than 85 percent of the pupil intake could belong to Group I and/or Group III in the Medium of Instruction Assessment Grouping. The grouping would be based on pupils' performance in their respective grade 5 and 6 internal school assessments in two subjects, Chinese and English. Group I pupils would be those within the top 40 percent of Chinese and English as a subject. Group III would be those within the top 40 percent of one subject and within the top 50 percent of the other subject.

2. Teachers had to be able to conduct classes in English effectively; the school principal would be responsible for certifying teachers' capabilities.

3. The school had to have programs and strategies in place to help secondary 1 (grade 7) pupils switch from learning in Chinese to learning in English.

13 Accompanying the new language policy were at least four supplementary initiatives: introduction of Putonghua (Mandarin) as a compulsory subject, Chinese and English Extensive Reading Scheme, Native English-Speaking Teachers (NET) Scheme and a compulsory language aptitude test for teachers. Of these initiatives, the aptitude test for teachers drew the most heated debate in Hong Kong. This was a new benchmark test that arose from Education Commission Report No. 6. (Education Commission, 1996) The benchmark test required that all English and Putonghua teachers - both new and existing — pass the main components of the Language Proficiency Assessment for Teachers (LPAT). It also required that teachers of English as a subject write five papers (on reading, writing, listening, speaking and language assessment) and teachers of Putonghua as a subject write four papers (on listening and recognition, pingyin, speaking and language assessment). The LPAT included an action plan to raise language standards designed by the Standing Committee on Language Education and Research (SCOLAR) in 1996. The action plan stipulated that all language teachers joining the profession in 2004-05 hold a Bachelor of Education degree majoring in the relevant language or another degree plus a postgraduate diploma in Education majoring in the relevant language. The LPAT and the SCOLAR reform invited strong opposition from the Professional Teachers Union (Glenwright, 2005). 
- Secondary schools opposed the reform because it took away their freedom of language choice and affected enrolment. Among the 404 public and aided secondary schools, 124 applied for an exemption to remain an English school. Of the 124 applications, 100 were approved. Of the 24 rejected cases, 20 appealed the decision and all publicly declared their anxiety regarding recruitment for the next academic year. ${ }^{14}$

- Pupils, especially those from the 24 rejected cases, were outraged by the reform. They viewed the switch from English to Chinese as a downgrading of their school. To show their dissatisfaction, they launched campaigns, held press conferences and sent letters to the $^{\text {press. }^{15}}$

- Parents rallied and petitioned the decision of the Education Board. They protested, launched letter-writing campaigns and placed an advertisement in the local newspaper. ${ }^{16}$

- Some groups, such as the Hong Kong Education Policy Concern Organization, urged the government to delay the reform for three years until teachers could be properly

\footnotetext{
${ }^{14}$ Jockey Club Ti I Secondary School, one of the 24 rejected schools, revealed to the press that its applications for admission dropped from 700 in 1996 to 13 in 1997, upon the announcement of its status change from an English to a Chinese school. The principal of another school (Tuen Mun Madam Lau Kam Lung Secondary School) shared the concern regarding applications for admission. The rejected schools delivered a petition signed by 1,600 parents and 1,000 pupils, as well as dozens of letters criticizing the language policy (Chan, 2002).

15 "We strongly request the continuation of teaching in English," stated pupils from Pope Paul VI College. "On what basis have we been disqualified? We question the vetting criteria! It is insensitive to the wishes of the school, parents and pupils!” (Ming Pao Daily News, Dec. 4, 1997). The student union of St. Antonius Girls' College collected 1,000 signatures in support of its appeal to the Education Board (Ming Pao Daily News, Dec. 13, 1997).

${ }^{16}$ A group of parents from Salesian English School held a letter-writing campaign to have the decision of the Education Board rescinded (Poole, 1997). The alumni of St. Louis School raised money to purchase a newspaper advertisement to make their discontent public (Delfino, 1997). Parents considered taking their cases to the Equal Opportunities Commission, accusing the Education Board of depriving their children of the right to learn in English. Some parents also protested outside the Education Board's headquarters (Kwok, 1997).
} 
trained to teach in Chinese. Others suggested that schools be allowed to choose the medium of instruction on a subject-by-subject basis. ${ }^{17}$

- Interestingly, teachers were silent on the subject of the reform, mostly because their attention was diverted to the new benchmark test. ${ }^{18}$

\subsection{Government counter-reaction and implications}

Despite the public outcry, the SAR government did not back down. However, the government softened its position by accepting all 20 of the appeals launched. ${ }^{19}$ The government instituted four additional measures to assist the English schools in making the switch to Chinese. In addition, it made the DSS funding formula more attractive for aided schools. ${ }^{20,21}$

\footnotetext{
${ }^{17}$ Yau Ma Tei Kai Fong Association, a neighbourhood association, protested and won the right to offer informal classes in English for non-Chinese-speaking children who could not afford the tuition charged by international schools.

${ }^{18}$ The Professional Teachers' Union resisted the LPAT through various collective actions, including the collection of the signatures of 37,000 language and non-language teachers, a public denunciation of the LPAT by over 1,000 teachers, press conferences and newspaper advertisements sponsored by teachers, and four public demonstrations (one of which was supported by six civil service associations). Despite the public outcry, the LPAT was eventually implemented (in 2001). The first test, held in March 2001, attracted 413 English and 304 Putonghua candidates, of whom 30 percent were serving teachers and 70 percent were prospective graduates of the Hong King Institute of Education or non-serving teachers (Law, 2003). The overall pass rate for English teachers was 65 percent (Glenwright, 2005).

${ }^{19}$ Regarding LPAT, the government also softened its position by revising the timeline. The first LPAT was postponed to March 2001. In addition, teachers were given three choices: (1) pass the LPAT, (2) pass the training courses recognized by the government, or (3) apply for an exemption (which was previously unavailable). To be exempted, English teachers had to hold a relevant and recognized degree with "substantial components on the study of English and its use" and recognized initial teacher training "with specialization in English and supervised English-teaching practice.” The government estimated that about 3,500 (out of 14,500) English-language teachers could be exempted. The first round of applications for exemption came in 2001. The applications of fewer than 1,600 English teachers and some 500 Putonghua teachers were successful.

${ }^{20}$ Under the new funding formula, the government raised the maximum tuition to 2.33 times the unit cost. In 2001-02 a DSS secondary school could charge as much as $\$ 68,000$ per pupil annually, while a DSS primary school could charge $\$ 48,000$. The government also required those DSS schools whose tuition exceeded $\$ 20,000$ to set aside money for scholarships to support pupils from low-income families.

${ }^{21}$ The four measures were:
}

1. Schools whose applications for admission dropped dramatically were granted an extension to admit pupils for the next academic year.

2. The Secretary for Education and Manpower announced a package to help schools teach in Chinese. Schools switching from English to Chinese had priority for grants and extra funding.

3. The government announced that English schools would be permitted to run a Chinese-language stream for pupils who had difficulty learning in English.

4. The government changed the funding formula for schools under the DSS, making it more attractive for aided primary and secondary schools. 
The policy reform had at least five implications. First, public and aided secondary schools became stratified into a small stream of English schools and a large group of Chinese schools; this stratification reversed the historic pattern. Second, the new DSS funding formula opened a channel for aided schools to reclaim their autonomy with respect to the curriculum and the language of instruction. ${ }^{22}$ Third, a number of aided schools that could not afford the switch to DSS opted into the "through-train” scheme. Under this scheme, the secondary school would form affiliations with and admit pupils directly from some primary schools within its school district — thus education services became bundled into a package across the primary and secondary levels. In this way, the secondary school could determine its enrolment. Fourth, the policy reform, together with its supplementary education initiatives, caused uncertainty and confusion among parents. As a result, parents shifted their preference from public and aided schools to private and international schools, which were better able to exert control over the quality of teachers and the school curriculum. ${ }^{23}$ Fifth, and most importantly, the impact of the reform cascaded over the entire education system, affecting primary schools most especially. Because admission to secondary schools was dependent on the primary school district, the reform had the effect of subtly placing primary schools at the centre of the language controversy. ${ }^{24}$

\section{The Model}

\footnotetext{
${ }^{22}$ Since 1999, at least 40 formerly aided schools had already switched to DSS funding. The decision to do so has had profound geographic implications: Revenues of DSS schools depend on both government subsidies (based on enrolment) and tuition. DSS schools located in high-income areas had no difficulty attracting enrolments; however, aided schools in public-housing areas could attract hardly any enrolments if they switched to DSS.

${ }^{23}$ In October 1999 Hong Kong Island School, a U.S.-oriented international school, reported its largest enrolment ever. Close to 2,500 pupils had registered for the 1999-2000 school year. The increase in demand for English schools led to a plan by the English School Foundation to build two new schools in order to accommodate increased enrolment by local children.

${ }^{24}$ Local newspapers reported that parents pushed their children at age three to take courses and acquire interview skills in order to increase their chances of grade 1 placement in a private school or a through-train primary school associated with an English secondary school (Sweeting, 2004, p. 544). Some parents admitted to the local press that, in order to enrol their children in a reputable primary school and progress to an English secondary school, they borrowed the home addresses of friends and relatives living in the relevant school district.
} 
The 1997 policy reform gave rise to voluminous education studies focusing on the causal effect of mother-tongue teaching and pupils’ school performance. However, the spatial implication of the reform remains unclear. The focus of the empirical model is to assess the change in the hedonic house price for proximity to primary schools — the main gateway to English secondary schools — and estimate the marginal bid function for proximity. Details of the model are discussed below.

\subsection{The hedonic regression model}

The hedonic regression is motivated by the standard model of an intrametropolitan housing market (Case and Mayer, 1996). Assume that households are perfectly mobile and choose among a given set of locations belonging to different school districts. Each school district has a fixed supply of land and housing. Households derive utility from consuming housing, neighbourhood amenities and nonhousing goods as a composite. Further assume that housing and non-housing goods have an inelastic supply and that households have convex utility functions. Under these assumptions, we can express house prices as a function of household income, property and neighbourhood characteristics.

For example, suppose there are $K$ housing markets. For a given market, $k$, assume that the price of the $i$-th property, $Y_{i k}$, is a function of the property's physical characteristics, $X_{i k}$, location $L_{i k}$, neighbourhood attribute $N_{i k}$ and distance (proximity) to the neighbourhood primary school, $Z_{i k}$. A general specification of $Y_{i k}$ is given as follows:

$g\left(Y_{i k}\right)=f\left(X_{i k}, L_{i k}, N_{i k}, Z_{i k} ; \theta\right)$,

where $\theta$ is a vector of parameters to be estimated.

There is no consensus on the best specification for $f$ and $g$. Common specifications include at least three types: log-log, semi-log and a general case that is based on the Box-Cox transformation, 
which includes as specific cases the log-log and semi-log forms based on the parameter $\lambda .{ }^{25} \mathrm{We}$ initially estimated the hedonic model using the Box-Cox transformation. The result provided an estimate of $\lambda=0.1$, which was not significantly different from zero; therefore, we use the semi-log specification for the hedonic model. The specification is given as follows:

$\log \left(Y_{i k}\right)=X_{i k} \theta_{x}+L_{i k} \theta_{L}+N_{i k} \theta_{N}+Z_{i k} \theta_{z}+u_{i k}$

The term $u_{i k}$ is the residual, which is assumed to have a mean of zero and standard deviation $\sigma$.

The model is estimated separately for two markets: Hong Kong Island and the Kowloon Peninsula, with $K=2$ (Figure 1).

\subsection{The marginal bid function}

Assume that the spatial distribution of primary schools in each market is exogenous. The hedonic function and the bid function characterize the way in which distance to the school, $Z_{k}$, is allocated among households. In particular, estimates from the hedonic function can be used to compute the marginal bid for being closer to a primary school. The marginal bid $W_{i}$ is the marginal willingness to pay for proximity and is defined as:

$W_{i}=\frac{\partial \hat{Y}_{i}}{\partial Z_{i}}=B_{0}+B_{1} Z_{i}+B_{2} X_{i}+B_{3} D_{i}+e_{i}$,

${ }^{25}$ Cropper, Deck and McConnell (1988) find that certain versions of the Box-Cox model perform best, although the log and linear models perform well when the house price model is misspecified. Cassel and Mendelsohn (1985) point out that the Box-Cox model may not be preferable when the objective is to obtain the best parameter estimates rather than the best-fit model. 
where $Z_{i}$ is the distance measurement, $X_{i}$ is the individual's expenditure on commodities other than $Z_{i}, \hat{Y}_{i}$ is the predicted hedonic price and $D_{i}$ is a set of demand shifters. The term $e_{i}$ is the disturbance, which is assumed to be uncorrelated with $u_{i k}$.

\section{Data and Variables}

Data for estimating the model are drawn from four sources. First, transaction data were acquired from one of the largest local realtors in Hong Kong. The transaction data consisted of 7,000 sales randomly picked from Hong Kong Island and the Kowloon Peninsula, of which half took place in 1996 and half in 2001. The two samples represented 6.9 and 16.4 percent of the total number of transactions in Hong Kong in 1996 and 2001, respectively. In 1996 the property market in Hong Kong was rising rapidly from the trough of a price cycle, with an average property price of $\$ 4,500$ per square foot. The market reached its peak in mid-1997 but dropped dramatically during the financial meltdown in October 1997. In 2001 the average price bottomed at around \$2,200 per square foot (Figure 2).

The transaction data provide information on price per square foot, street address and the physical characteristics of the property. Physical characteristics include age of the building, floor number and the estate to which the property belongs. ${ }^{26}$ Older buildings are expected to sell at a lower price; flats on upper floors will sell at a higher price. Units from a large estate might have an ambivalent influence on sell price. On the one hand, prices might be higher because large estates are often constructed by reputable builders with higher standards of quality. On the other hand, a largescale development could mean a greater supply of near-identical units, a situation that depresses the sell price. The database also contains information on the property's days on market. Properties with longer days on market tend to be associated with lower prices.

\footnotetext{
${ }^{26}$ An estate is a large-scale private residential development. An example would be Mei Fu Sun Chun in the Kowloon Peninsula. This estate was developed between 1965 and 1978 in eight phases. It comprises 99 towers with 13,500 flats ranging in size from 600 to 1,800 square feet.
} 
The second source of data is the map of the mass transit railway (MTR) system in Hong Kong. The MTR is the subway system. We use the map of the MTR stations to create location variables for the model. To do so, we first geocode the properties’ street addresses against Hong Kong’s street network file provided by MapInfo StreetPro and then extract the latitude and longitude coordinates of the 7,000 sales. For each transaction, we calculate the distance to the nearest MTR station. This distance variable serves as a proxy for accessibility because the MTR is one of the major transportation networks in Hong Kong. ${ }^{27}$ For each property, we create another variable that measures the distance to Central, which is Hong Kong's central business district (CBD). Both distance variables are expected to exert a negative influence on sell price.

The third source of data is the online school database. Primary school information is obtained from the Web page of the Education and Manpower Bureau. School addresses are recorded and geocoded in order to compute the distance between each transacted property and its nearest primary school. Ideally, one would simply use school district boundaries to match each property with its school district (Black, 1999; Bogart and Cromwell, 1997, 2000; Cheshire and Sheppard, 2004). Two factors might render the use of school district boundaries ineffective. First, district boundaries follow irregular blocks and can change year to year; for parents, distance to the nearest school tends to be a more stable and reliable check for primary school admission. Second, school districts cover a broad spatial scale; each district contains five bands of secondary schools. ${ }^{28}$ If the model uses only school districts to examine the hedonic price for a good school, the price premium for a band one school could be offset by the price discount for a band five school at the school district level. For these reasons, we focus our model on distance to the nearest school.

\footnotetext{
${ }^{27}$ Between 1996 and 2001 seven new MTR subway stations were developed, for a total of 43 stations.

28 Technically, “school bands” refers to the quintiles of pupils' academic performance (see section 2.2). In reality, residents of Hong Kong label and stigmatize secondary schools by the band of grade 6 pupils they consistently admit for example, band one secondary schools refers to schools that consistently admit pupils in the top quintile.
} 
The school data contain information on whether or not the primary school is linked to a secondary school, by either the through-train scheme or a feeder arrangement. ${ }^{29}$ If the primary school is linked to a secondary school, the language designation of the secondary school is obtained from that school's Web page. A dummy variable is created to identify English secondary schools. Since English secondary schools are perceived as offering education of a better quality, one would expect a price premium for properties closer to primary schools that are linked to English secondary schools. Henceforth, we refer to primary schools that are linked to English secondary schools as EMI-linked primary schools.

The final source of data is the census profiles for small town-planning units (STPUs). An STPU is the smallest geographic unit used by the Hong Kong Census and Statistics Department to release census information. Census information is obtained for 1996 and 2001 to create the demand shifters in the bid function. These variables include average age of household head, average household size and average household income. The variable that measures the average household food expenditure, a proxy for non-housing expenditure, is obtained from the 1996 and 2001 issues of the Consumer Expenditure publications. Key variables are summarized in Table 2.

\section{Estimating strategy}

\subsection{Overall estimating issues}

The model has two objectives. The first is to estimate the marginal bid for each unit distance closer to a primary school. The second is to compare the marginal bid (a) between primary schools that are EMI-linked and those that are not; (b) among public, aided and private schools; and (c) before and after the 1997 policy reform.

To achieve the first objective, we follow the conventional approach and execute the model in two stages. In the first stage, we estimate the marginal price of being closer to a primary school,

\footnotetext{
${ }^{29}$ Feeder schools are schools that comprise both a primary and a secondary section.
} 
based on the usual hedonic regression model. In the second stage, we use the results from stage one to estimate the marginal bid function for proximity to primary schools.

The formal contributions to hedonic price theory and estimating marginal bid function were generally attributed to Rosen (1974). Hedonic price theory suggests that the price of a property is an aggregate of the implicit price of individual attributes bundled in the property. Using the implicit prices of individual attributes, Rosen analyzed the estimation problem of consumers' marginal bid and supplies' supply for a particular attribute as a standard identification problem, which could be solved by simultaneous estimation methods such as two-stage least squares (2SLS). Applying 2SLS to the marginal bid (supply) function requires the assumption that consumer (supplier) characteristics are appropriate instruments for the endogenous variables in the marginal bid (supply) function.

Rosen’s approach has a major shortcoming. Marginal prices constructed from stage one do not add new information, a requirement for identification in the second stage (Brown and Rosen, 1982). Two most commonly adopted solutions are the use of a priori restrictions on functional form (Chattopadhyah, 1999) or the use of segmented markets (Brasington and Hite, 2005; Brasington, 2000, 2003). In the present study, we follow the latter approach and provide a formal Chow test for testing structural differences in the market segments. ${ }^{30}$

To achieve the second objective, we note that the 1997 policy reform can be seen as a natural experiment. This allows us to divide the 1996/2001 pooled sample into "control” and "treatment" groups. One can separate the houses into those that were sold in 1996, before the reform (control), and those that were sold in 2001, after the reform (treatment). One can separate the properties into those whose nearest primary schools are not and are linked to EMI secondary schools (control and treatment, respectively). One can separate the transactions into those whose nearest primary schools

\footnotetext{
${ }^{30}$ Recent years have seen a surge in the use of functional-form restriction or market segmentation to identify the demand for environmental goods. See Brasington and Hite (2005), Chattopadhyay (1999), Chay and Greenstone (2005), Cohen and Coughlin (2008), for example.
} 
are public or aided (control) and those whose nearest primary schools are private, DSS funded or ESF operated (treatment). Henceforth, "private schools” refers to all private, DSS and ESF schools.

To identify the control and treatment groups, we create six dummy variables and multiply each of them into the straight-line distance (in 100 metres) between the transaction and its nearest primary school. The first dummy variable, year 2001, equals one if the flat was sold in 2001 and zero otherwise. The second dummy variable, EMI-linked, equals one if the flat's nearest primary school is linked to an English secondary school and zero otherwise. The third dummy variable, private primary school, equals one if the nearest primary school is private and zero otherwise. The fourth, fifth and sixth dummy variables — the focus of the present study — are EMI-linked x year 2001, private primary school x year 2001 and private primary school x EMI-linked x year 2001. These dummy variables are multiplied into the variable that measures distance to the nearest primary school; the variables allow us to compare the marginal market price and the bid for proximity to private and EMI-linked schools, before and after the policy reform.

To identify the impact of the policy reform, we include in the hedonic model the structural characteristics of the apartment, neighbourhood attributes and estate fixed effects, distance to the CBD, and nearest MTR station. Note that all distance variables are subtracted from an arbitrary constant of five kilometres such that the distance variables are interpreted as each 100 metres closer to the nearest primary school, the CBD or the nearest MTR station (Zabel and Kiel, 2000). ${ }^{31}$

\subsection{The hedonic model}

Estimation of the hedonic regression model involves two estimating issues. First, it is well known that days on market is endogenous — that is, transacted prices and days on market are jointly determined. To deal with this endogeneity issue, we estimate the hedonic model using 2SLS, with the season during which the property is sold as the instrument.

\footnotetext{
${ }^{31}$ The results are robust to the choice of the arbitrary constant (Zabel and Kiel, 2000).
} 
Second, to ensure that the principal influence of any change in property prices is captured by the variable that directly measures the policy innovation, we test the hedonic model using two alternative specifications. The first specifies separate hedonic models for the 1996 and 2001 samples. This alternative specification tests whether the estimates are consistent for other coefficients. The second alternative specification includes in the hedonic model the variable that captures the language of instruction of the nearest secondary school. Because primary schools are the principal channel determining pupils’ allocation to a secondary school, one expects that the hedonic estimates will be robust to including secondary school information.

\subsection{The marginal bid function}

The marginal bid for each 100 metres closer to a primary school can be estimated using the marginal prices from the estimated hedonic regression model. The marginal bid is regressed on distance to the nearest school (subtracted from the arbitrary constant of five kilometres), non-housing expenditure and demand shifters. The non-linearity of the hedonic function allows households to choose both distances and marginal prices for proximity — for example, households that place a greater value on education might choose to live closer to EMI-linked primary schools and bid higher for proximity. In this case, ordinary least squares (OLS) estimates of the marginal bid function will be biased (Bartik, 1986, 1987).

To consistently estimate the marginal bid function, we use a 2SLS approach, using the district dummy for Hong Kong Island (versus the Kowloon Peninsula) as the instrument. We assume that the district dummy exogenously shifts the household budget constraint but is uncorrelated with households' valuing of education — that is, we assume that the hedonic function varies across districts and that average valuing of education do not. ${ }^{32}$ We add other instruments by multiplying the

\footnotetext{
${ }^{32}$ We perform the Chow test to test whether the two districts, Hong Kong and Kowloon, can be pooled. The error sum of squares is 319.5584 for the separate Hong Kong hedonic model and 244.1322 for the Kowloon model. The pooled model has an error sum of squares of 575.6480 . Altogether, there are $\mathrm{k}=45$ parameters, with a total sample size of $\mathrm{n} 1+\mathrm{n} 2=7,000$.
} 
district dummy with the demand shifters, including household size, household size squared, household age and household age squared.

For the demand shifters, ideally one would obtain variables at the household (consumer) level; however, such information is unavailable for the present study. Instead, we create demand shifters using areal averages of the neighbourhood (STPU) in which the transaction is located. In doing so, we implicitly assume that the number of transactions in each STPU is small relative to the housing stock such that the transactions do change the spatial average of the demand variables in the STPU. Because the demand variables are spatial averages, we interpret the bid function as the willingness-to-pay function of the average resident in a neighbourhood. Estimates for the demand shifters will show the extent to which changing the average neighbourhood characteristics might shift (up or down) the bid function across STPUs.

In sum, we first estimate a semi-log form of the hedonic regression model for house prices, by applying the 2SLS technique to account for the endogeneity of days on market. Using the results from the hedonic model, we calculate the marginal bid for each 100 metres closer to a primary school — public and aided, private, EMI-linked/not EMI-linked — by computing the marginal hedonic price. We then estimate a 2SLS model for the marginal bid function for proximity to various types of primary school.

\section{Results}

Table 3 presents the estimated hedonic price model. Table 4 displays the estimated marginal bid by types of school. Table 5 summarizes the results of the bid function.

\subsection{Hedonic analysis}

The Chow test statistic is 3.2573, against the F-critical value of 1.5576 at the 1-percent significance level; therefore, the test result allows us to reject the null hypothesis of identical parameters in the two separate hedonic models for Hong Kong and Kowloon. 
The preferred approach is the regression that uses the pooled sample, whose results are reported in Table 3, column (V). Standard errors are reported in parentheses; double asterisks identify estimates that are significant at the 5-percent level. The focus is on the variable distance to primary school and its interaction with the dummy variables EMI-linked primary school, private primary school, private EMI-linked primary school and year 2001. In column (V), the model controls for structural, neighbourhood and school characteristics but excludes secondary school information. It has an $R$ squared of 0.58 .

The results show that, in 1996, apartments that are closer to primary schools, and particularly private primary schools, tend to sell higher than those that are further away. The coefficient of distance to primary school shows the implicit price for each 100 metres closer to a primary school in 1996. It is positive and significant. For each 100 metres closer, the transacted price tends to rise by 3.83 percent. Its interaction with the variable private primary school is also positive and significant. The estimate shows that the apartment would sell higher at a premium of $4.08(=3.83+0.25)$ percent for each 100 metres closer to a private primary school.

The 2001 implicit value of proximity to any primary school is not significantly different from the 1996 value; however, the 2001 implicit value of proximity to a private primary school is higher than the 1996 value. This result is shown by the fact that the variable distance to primary school $\mathrm{x}$ year 2001 is insignificant and that private primary school x year 2001 is positive and significant (at the 10-percent level). For each 100 metres closer to a private primary school, the premium is an additional 0.02 percent in 2001 compared to transactions made in 1996.

Apartments that are close to EMI-linked primary schools do not sell significantly higher in 2001 than the average school in 1996; however, those that are near private EMI-linked primary schools do sell higher in 2001 than in 1996. This observation is supported by the result that EMIlinked primary school is insignificant but that its interaction with year 2001 is positive and 
significant. The additional premium for a private EMI-linked primary school is 0.14 percent of the transacted price in 2001, compared to a similar apartment sold in 1996.

To lend context to the estimates, consider the average apartment in the pooled sample. The average sell price is $\$ 3,557.83$ per square foot and the average size of an apartment is 711.79 square feet. The average apartment is 420 metres from a primary school. The total sell price of the apartment in 1996 is $\$ 2,532,410.03$. If the apartment is 100 metres closer to its neighbourhood primary school, it will sell for an additional \$96,991.30; if the primary school is linked to an EMI secondary school, the transaction will carry an additional premium of $\$ 795.72$, with a sell price of $\$ 2,630,106.33$. On the other hand, a private school would add a premium of \$6,331.03; an EMIlinked private school would further add \$759.72, giving a total of \$2,637,251.08.

If the transaction occurs in 2001, the distance premium adds another \$3,798.62 for each 100 metres closer to a primary school; the 2001 transacted price becomes $\$ 2,633,199.95$ (= $\$ 2,532,410.03+\$ 96,991.30+\$ 3,798.62)$. If the 2001 transaction is near an EMI-linked or a private primary school, the transacted price would be $\$ 506.48$ higher. If the private school is also EMIlinked, it will sell for \$3,545.37 more than in 1996. In sum, an apartment would sell for \$8,356.95 more in 2001 than in 1996, for each 100 metres closer to a private EMI-linked primary school. ${ }^{33}$ We check the robustness of the results by comparing the estimates with those under the alternative specifications (Table 3). Four notes follow. First, the model results are robust to the inclusion of secondary school information. In column (VI), we include in the model distance to the nearest secondary school and English secondary school, and the model estimates hardly change. Second, we estimate the model for the 1996 and 2001 sample separately; see columns (I) and (III). Estimates for primary school variables are consistent with those reported in column (V). Third, note that all other variables receive consistent estimates for the 1996 and 2001 samples (Appendix 2).

\footnotetext{
${ }^{33}$ While a figure of $\$ 8,356.95$ might seem immaterial in the context of an apartment worth $\$ 2$ million, it should be kept in mind that the median monthly salary in Hong Kong is $\$ 8,000$ to $\$ 9,000$. Meanwhile, according to the Hong Kong Council of Social Services, for every 100 children under the age of 15, almost 25 live in families with earnings below the first quartile.
} 
Finally, comparing the results in columns (I) and (III) with those in columns (II) and (IV), one finds that the inclusion of secondary school information in the separate 1996 and 2001 model does not affect the model estimates.

We test the endogeneity of days on market using the Durbin-Wu-Hausman (DWH) test (Davidson and MacKinnon, 1993). In essence, the DWH test is an augmented regression test because it first regresses days on market on all exogenous variables and then includes the first-stage error in the second-stage OLS regression. If the coefficient for the first-stage error is significant, then the OLS estimates in the second stage will be inconsistent. In the present study, we find that the pvalue for days on market is large (0.92); therefore, OLS estimates are consistent for the hedonic model.

\subsection{Marginal bid analysis}

We estimate a separate hedonic price function for each district (Hong Kong Island and the Kowloon Peninsula) using the pooled sample. We use the implicit marginal price of distance to the nearest primary school to compute the marginal bid for proximity to the school (Table 4). We then estimate the marginal bid function, with distance to school and non-housing expenditure being endogenous. Table 5 reports the estimates of the marginal bid function using 2SLS techniques. The $R$-squared ranges from 0.26 for the entire pooled sample to 0.29 for the sample of EMI-linked primary schools and 0.27 for private schools. $R$-square is highest (0.37) for private EMI-linked primary schools.

The results show that households spending more on non-housing items tend to bid less for proximity to public or aided primary schools and more for proximity to private schools. Households with higher incomes also bid higher for proximity to private primary schools. While larger households tend to bid more for public or aided schools, smaller households bid more for private schools. Similarly, older households bid more for public or aided primary schools. 
The variable year 2001 (interacted with distance to primary school) is insignificant for the bid function for primary schools in general but positive and significant for private schools. Its magnitude is greatest for the subsample of private EMI-linked schools. These results provide evidence supporting our hypothesis: In 2001 households seem to have shifted away from public education and to bid more for private schools, especially those that are linked to EMI secondary schools.

Critics might initially suspect that the marginal bid for proximity to EMI-linked primary schools should be similar before and after the 1997 reform, for two reasons. On the one hand, the talk about the 1997 language reform began in the early 1990s. The reform did not happen overnight. At the same time, the 100 English secondary schools have long been recognized as the top, elite schools by the public; the policy reform could not be an innovation that shocked the market. Instead, it could be considered as a relabeling exercise of the existing level of school quality. In both cases, concerned parents could have already moved to a better school district prior to the policy announcement in 1997.

We offer two reasons that might explain the significant difference between the pre- and postreform marginal bid. First, despite the fact that discussion of the policy reform occurred in the early 1990s, media coverage had been negligible. Both parents and the schools remained uninformed (Sweeting, 2004). It was not until 1997 that the policy reform was firmly executed that parents started to react to the new language policy.

Second, note that those households who tend to bid higher for EMI-linked primary schools and private schools are smaller, younger and wealthier. They tend to be less experienced parents, who are actively acquiring information about the education system. Larger households with more children might have already moved to the desirable school district when making their school decisions for the first-born. 
How well does the district dummy serve as the instrument for distance to primary school? In terms of relevance, the district dummy contains only two levels; therefore, the correlation coefficient between district and distance is meaningless due to the small number of variations in the district dummy. Nonetheless, our results show that the district dummy is significant at the 5-percent level in the first stage of estimating the bid function (the coefficient estimate is -0.19 with a p-value of 0.01). ${ }^{34}$ In terms of exogeneity, the instrument passes the over-identification test. The Sargan test, whose null hypothesis stipulates that the instrument is exogenous, reveals a test statistic of 25.9 for the overall sample, 26.78 for the subsample of EMI-linked primary schools, 25.38 for private schools and 23.29 for private EMI-linked primary schools; the test statistic is distributed as $\chi^{2}$ with 26 degrees of freedom; the p-values are $0.47,0.42,0.50$ and 0.62 correspondingly. In all cases, we fail to reject the hypothesis that the instrument is exogenous. ${ }^{35}$

\section{Conclusions}

The present study assesses the spatial impact of the 1997 education policy reform in Hong Kong. It estimates a hedonic model of transacted prices and the marginal bid function for proximity to primary schools. The results provide evidence supporting our hypothesis: The 1997 policy reform might have increased the demand for private education, especially private primary schools linked to

\footnotetext{
${ }^{34}$ Results are available upon request.

${ }^{35}$ One might question whether spatial lag and/or spatial error could serve as alternative model specifications (Brasington and Hite, 2005; Cohen and Couglin, 2008). In terms of the spatial lag model, one has to be mindful that its conceptual underpinning is the substitutability of neighbouring dwelling units. In the case of Hong Kong, an extremely densely populated city, one can argue conceptually it is unlikely that such underpinning could hold because of the frequent demolition and reconstruction of apartment buildings in both old and new districts. For example, a simple 500-meter walk on the Hong Kong island - a small block in most North American cities — could already canvass more than 20 tall and skinny apartment buildings, whose age ranges between less than 5 to more than 30 years. For this reason, the applicability of a spatial lag model becomes questionable; instead, estate fixed effects could be more prominent in influencing property prices. Technically, this point is confirmed by conducting an LM test for spatial lag for the two districts separately. The spatial lag variable is the average selling price per square foot of preceding transactions within a 300 -meter cutoff. The test statistic is distributed as $\chi^{2}(1)$, with a critical value of 6.635 at the 1-percent significance level. The resulting test statistics are.2.1311 and 3,0021 for the Hong Kong and Kowloon model, respectively. Both test statistics suggest a failure to reject the null hypothesis of the absence of spatial dependence. In terms of spatial error, the Moran's I test statistics are 1.2202 and 1.0131 for the hedonic (pooled) and marginal bid functions, respectively. Both test results suggest a failure to reject the null hypothesis of the absence of spatially autocorrelated errors.
} 
English secondary schools. The results show that the marginal bid for proximity to private English schools increased by 2 percent after the reform. On average, homeowners are willing to pay HK $\$ 8,400$ for each additional 100 metres closer to a private EMI-linked primary school.

The study reveals that school districts have demarcated the housing market of Hong Kong into distinctive submarkets and that the 1997 language reform represented a local change within each submarket. In order for the policy innovation to exert an influence on transacted house prices, the labelling effect of English schools could not possibly spillover to other school districts; instead, the effect must be contained within the local district. In an otherwise closed submarket in which the labelling effect could be felt across submarkets, the capitalization of being close to an English school could not have taken place.

The study draws implications for policy-makers: Education policies that are aspatial often have a spatial effect on welfare. The fact that a majority of the 100 English secondary schools are located on Hong Kong Island implies that increases in the bid for proximity to EMI-linked primary schools facilitate a redistribution of housing wealth to Hong Kong Islanders at the expense of residents of the Kowloon Peninsula — let alone residents of the New Territories. This spatial effect on welfare merits further research attention and requires more detailed socioeconomic data at finer geographic scales, if not at the home-buyer level.

The increased marginal bid for English education in 2001 reveals that, while the provision of vernacular education might be political, the demand for English education remains the preferred economic choice for children. This strong demand for English education is not surprising, in light of Hong Kong's role in the global financial market, an international appearance that requires workers to be proficient in English in order to stay competitive. The compulsory switch to vernacular education might eventually act as an incentive for wealthier parents to seek alternatives by either sending their children or moving the whole family to overseas for the pursuit of English education. 
As an epilogue, the 1997 policy reform represents a failure despite the government's own applause. In 2005 the SAR government conducted an interim review of the policy reform. The review assessed the performance of secondary 5 (grade 11) pupils on the Hong Kong Certificate of Education Examination (HKCEE), a public examination to determine pupils’ entrance to matriculation and, in some cases, pre-admission to university. Pupils sitting for the 2005 HKCEE were the first cohort of graduates after the fully implemented policy reform. The government review found that most pupils from vernacular schools performed slightly better in non-language subjects than those who wrote the 2002 HKCEE, the last cohort of secondary pupils admitted prior to the 1997 reform. Pupils from Chinese secondary schools performed more poorly in the English course specifically (Education Commission, 2005). The results stirred public reaction concerning the comparability of the 2002 and 2005 test questions and the scientific basis of the review. More importantly, Hong Kong’s postsecondary education was conducted mostly in English; educators found a general decrease in language proficiency among even the top vernacular secondary schools. Eventually, in April 2009, the government “fine tuned” the language policy and reverted back to the pre-reform arrangement: Secondary schools could use their discretion in choosing the medium of instruction in order to maintain the integrity and coherence of the curriculum. 


\section{References}

Angrist, J.D., and Lavy, V. 1999. Using Maimonides’ rule to estimate the effect of class size on scholastic achievement. Quarterly Journal of Economics, 114(2), 533-575.

Barrow, L., and Rouse, C.E. 2004. Using market valuation to assess public school spending. Journal of Public Economics, 88, 1747-1769.

Bartik, T.J. 1986. Neighbourhood revitalization's effects on tenants and the benefit-cost analysis of government neighbourhood programs. Journal of Urban Economics, 19, 234-248.

Bartik, T.J. 1987. The estimation of demand parameters in hedonic price models. Journal of Political Economy, 95(1), 81-88.

Berry, V., and McNeil, A. 2005. Raising English language standards in Hong Kong. Language Policy, 4, 371-394.

Black, S.E. 1999. Do better schools matter? Parental valuation of elementary education. Quarterly Journal of Economics, 114(2), 577-599.

Bogart, W.T., and Cromwell, B.A. 1997. How much more is a good school district worth? National Tax Journal, 50, 215-232.

Bogart, W.T., and Cromwell, B.A. 2000. How much is a neighbourhood school worth? Journal of Urban Economics, 47, 280-305.

Brasington, D. 1999. Which Measures of School Quality Does the Housing Market Value? Journal of Real Estate Research, 18(3), 395-413.

Brasington, D. 2000. Demand and Supply of Public School Quality in Metropolitan Areas: The Role of Private Schools. Journal of Regional Science, 40(3), 583-605.

Brasington, D. and Hite, D. 2005. Demand for Environmental Quality: A Spatial Hedonic Analysis. Regional Science and Urban Economics, 35(1), 57-82.

Brown, J.N. and Rosen, H.S. 1982. On the estimation of structural hedonic price models. Econometrica, 50(3), 765-768.

Card, D. 1995. Earnings, schooling, and ability revisited. Research in Labour Economics, 14, $23-48$.

Card, D., and Krueger, A.B. 1996. Labour market effects of school quality: Theory and evidence. NBER Working paper no. 5450. Cambridge, MA: National Bureau of Economic Research.

Case, K.E., and Mayer, C.J. 1996. Housing price dynamics within a metropolitan area. Regional Science and Urban Economics, 26, 387-407.

Cassel, E., and Mendelsohn, R. 1985. The choice of functional forms for hedonic price equations: Comment. Journal of Urban Economics, 18(2), 135-142. 
Chan, E. 2002. Beyond pedagogy: Language and identity in post-colonial Hong Kong. British Journal of Sociology of Education, 23(2), 271-285.

Chattopadhyay, S. 1999. Estimating the demand for air quality: New evidence based on the Chicago housing market. Land Economics, 75(1), 22-38.

Chay, K.Y. and Greenstone, M. 2005. Does air quality matter? Evidence from the housing market. Journal of Political Economy, 113(2), 376-424.

Cheshire, P., and Sheppard, S. 2004. Capitalising the value of free schools: The impact of supply characteristics and uncertainty. Economic Journal, 114, 397-424.

Cohen. J.P. and Coughlin, C.C. 2008. Spatial hedonic models of airport noise, proximity, and housing prices. Journal of Regional Science, 48(5), 859-878.

Colwell, P., and Guntermann, K. 1984. The value of neighbourhood schools. Economics of Education Review, 3, 177-182.

Cropper, M.L., Deck, L.B., and McConnell, K.E. 1988. On the choice of functional form for hedonic price functions. Review of Economics and Statistics, 70(4), 668-675.

Davidson, R., and MacKinnon, J.G. 1993. Estimation and Inference in Econometrics. New York: Oxford University Press.

Delfino, B., 1997. Schools ask why they failed. South China Morning Post, December 15, 1997, p.7.

Dimmock, C., and Walker, A. 1997. Hong Kong's change of sovereignty: School leader perceptions of the effects on educational policy and school administration. Comparative Education, 3(2), 277-302.

Education Commission. 1984. Education Commission Report No. 1. Retrieved in September 2009 from http://www.edb.gov.hk/index.aspx?nodeID=677\&langno=1.

Education Commission. 1986. Education Commission Report No. 2. Retrieved in September 2009 from http://www.edb.gov.hk/index.aspx?nodeID=677\&langno=1.

Education Commission. 1996. Education Commission Report No. 6. Retrieved in September 2009 from http://www.edb.gov.hk/index.aspx?nodeID=677\&langno=1.

Education Commission. 2005. Review of medium of instruction for secondary schools and secondary school places allocation. Retrieved in June 2005 from http://www.e-

c.edu.hk/eng/reform/resources/full_version-eng(27\%20Jan)-FINAL.pdf.

Evans, S. 2000. Hong Kong's new English language policy in education. World Englishes, 19(2), 185-204.

Evans, S. 2002. The medium of instruction in Hong Kong: Policy and practice in the new English and Chinese streams. Research Papers in Education, 17(1), 97-120. 
Friesen, J., and Krauth, B. 2007. Sorting and inequality in Canadian schools. Journal of Public Economics, 91, 2185-2212.

Glenwright, P. 2005. Grammar error strike hard: Language proficiency testing of Hong Kong teachers and the four "noes.” Journal of Language, Identity, and Education, 4(3), 201-226.

Hilber, C.A.L., and Mayer, C. 2004. Why do households without children support local public schools? NBER Working paper no. 10804. Cambridge, MA: National Bureau of Economic Research.

Ho, B., and Ho., K.K. 2004. The developmental trend of the medium of instruction in secondary schools of Hong Kong: Prospect and retrospect. Language and Education, 18(5), 400-413.

Hong Kong Board of Education. 1973. Report of the Board of Education on the Expansion of Secondary School Education in Hong Kong in the Next Decade. Hong Kong: Hong Kong Government.

Hong Kong Board of Education. 1974. Secondary Education in Hong Kong over the Next Decade. Hong Kong: Hong Kong Government.

Hong Kong Board of Education. 1997a. Report on review of Nine-Year Compulsory Education (revised version), October, 1997. Hong Kong: Hong Kong Government of the Special Administrative Region, People's Republic of China.

Hong Kong Board of Education. 1997b. Guidance on Secondary Schools’ Medium of Instruction. Hong Kong: Hong Kong Government of the Special Administrative Region, People's Republic of China.

Hong Kong Board of Education. 2002. Progress report on the education reform (1), January, 2002. Hong Kong: Hong Kong Government of the Special Administrative Region, People’s Republic of China.

Hong Kong Census and Statistics Department. 2005. Hong Kong digest of statistics, 2005. Hong Kong: Hong Kong Government of the Special Administrative Region, People's Republic of China.

Jud, G., and Watts, J. 1981. Schools and housing values. Land Economics, 57, 459-470.

Kwok, S. 1997. 20 Schools appeal over English ruling. South China Morning Post, December 16, 1997, p. 5.

Law, W.W. 2003. Globalization as both threat and opportunity for the Hong Kong teaching profession. Journal of Educational Change, 4, 149-179.

Ledwith, V. 2009. Open enrolment and student sorting in public schools: evidence from Los Angeles County. Environment and Planning A, 41, 1109-1128.

Midland Realty Hong Kong, 2009. Midland property price chart (MPPC). Retrieved in August 2009 from http://www.midland.com.hk/eng/m_index/main.shtml. 
Ming Pao Daily News, 1997a. Jung wen shu zhe zi zi xian fen lu (Chinese writings reveal anger). December 7, 1997, A10+.

Ming Pao Daily News, 1997b. Sheung Shu Chi Tzi Zhou Yi (Appeal deadline until Monday). December 13, 1997, A10+.

Poole, O. 1997. Past pupils to back English teaching bids. South China Morning Post, December 3, 1997, p. 5.

Rosen, H.S. 1974. Hedonic prices and the implicit markets: Product differentiation in pure competition. Journal of Political Economy, 82, 132-157.

Sweeting, A. 2004. Education in Hong Kong, 1941 to 2001. Hong Kong: Hong Kong University Press.

Sykes, B., and Kuyper, H. 2009. Neighbourhood effects on youth education achievement in the Netherlands: can effects be identified and do they vary by student background characteristics? Environment and Planning A, 41, 2417-2436.

Weimer, D.L., and Wolkoff, M.J. 2001. School performance and housing values: Using noncontiguous district and incorporation boundaries to identify school effects. National Tax Journal, 54, 231-253.

Zabel, J.E., and Kiel, K.A. 2000. Estimating the demand for air quality in four U.S. cities. Land Economics, 76(2), 174-194. 
Table 1 Number of schools by source of funding, 1994 and 2001

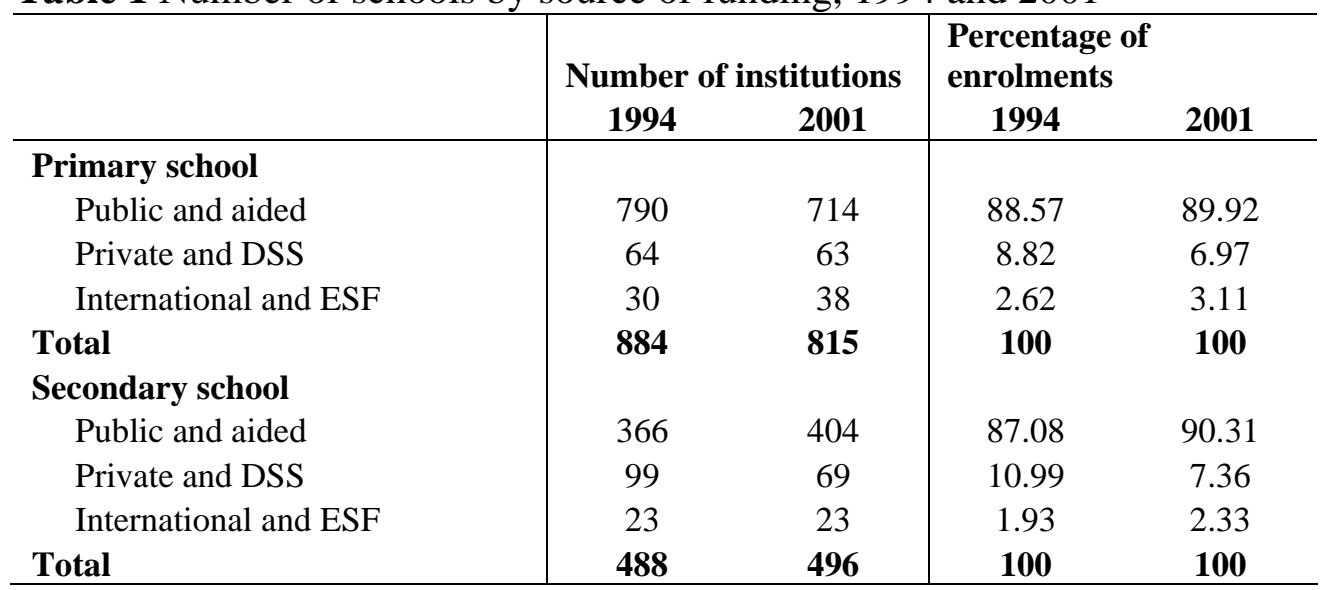

Source: Hong Kong Census and Statistics Department, 2005. 
Table 2 Summary statistics (selected variables)

\begin{tabular}{l|cccc}
\hline & $\mathbf{1 9 9 6}$ sample $(\boldsymbol{n}=$ & $\begin{array}{l}\text { 2001 sample }(\boldsymbol{n}= \\
\mathbf{3 , 5 0 0})\end{array}$ \\
Variables & $\mathbf{3 , 5 0 0 )}$ & $\begin{array}{l}\text { Standard } \\
\text { deviation }\end{array}$ & Mean \\
deviation
\end{tabular}

Notes: Price data are acquired from one of the largest local realtors in Hong Kong. School data are obtained

from individual school Web sites. All addresses are geocoded against the street network file acquired from MapInfo. Calculations by the authors. 
Table 3 Selected hedonic regression model estimates, by 2SLS

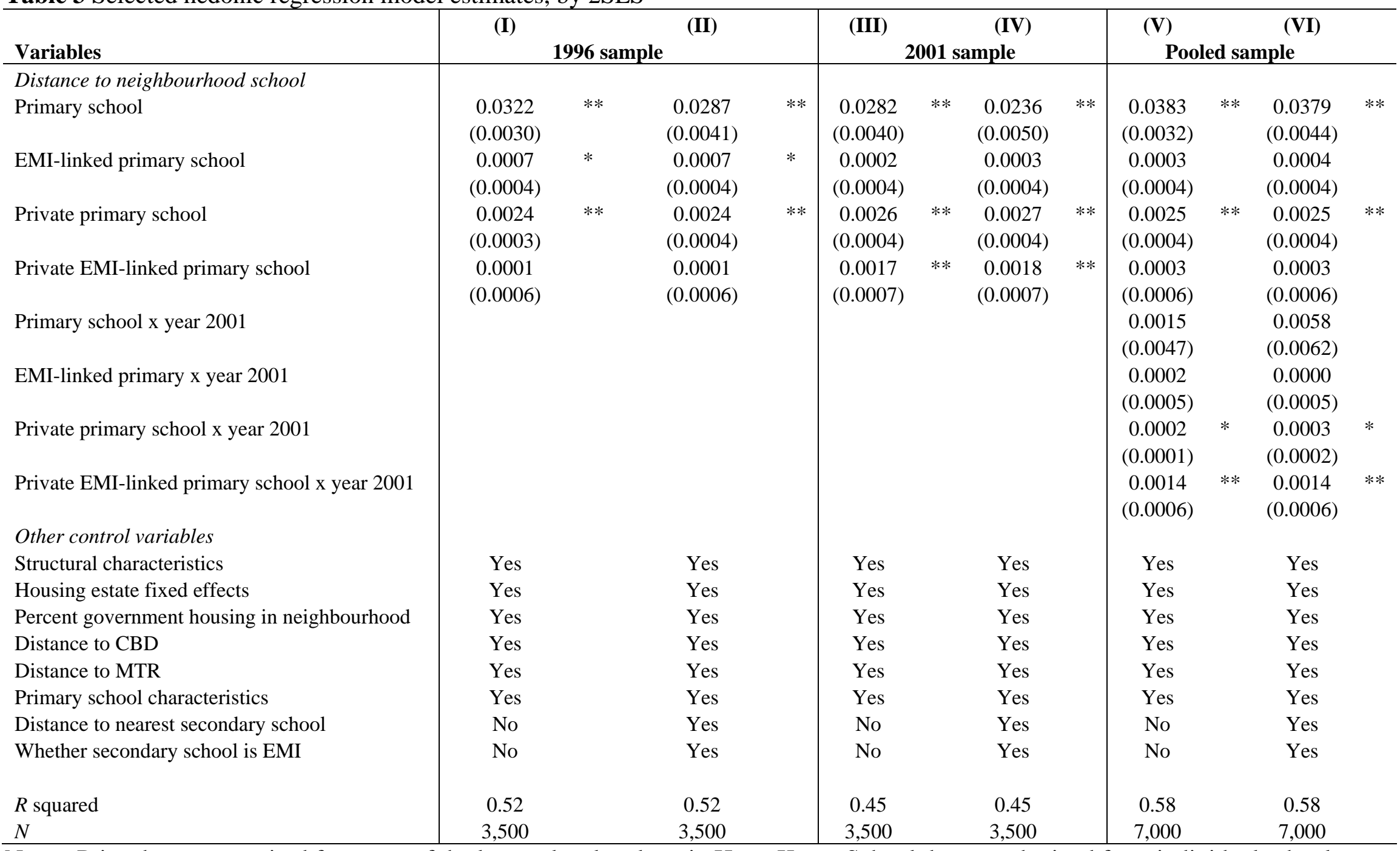

Notes: Price data are acquired from one of the largest local realtors in Hong Kong. School data are obtained from individual school Web sites. All addresses are geocoded against the street network file acquired from MapInfo. The dependent variable is the log of the per-square-foot sell price of a flat. All distances are measured in 100 metres and are subtracted from an arbitrary constant of five kilometres; they are interpreted as each 100 metres closer to the nearest school, an MTR station or the CBD. Structural characteristics include age of the building and the floor number. The model includes days on market, which is endogenous and is instrumented by the season in which the flat is sold. Standard errors are in parentheses. Single asterisks identify significance at the 10-percent level, double asterisks at the 5-percent level. See the Appendix for the full model. Calculations by the authors. 
Table 4 Predicted marginal bid as a percentage of sell price, 1996 and 2001

\begin{tabular}{l|cc}
\hline & 1996 sample & 2001 sample \\
\hline Predicted price per sq. ft. & $4,138.56$ & $2,715.85$ \\
Marginal bids (\% of predicted price) & & \\
Primary school & 2.96 & 2.11 \\
EMI-linked primary school & 3.03 & 2.13 \\
Private primary school & 2.35 & 3.15 \\
Private EMI-linked primary school & 1.62 & 3.26 \\
\hline
\end{tabular}

Note: Predictions are based on the 2SLS results in Table 2, evaluated at the pooled sample means. 
Table 5 Estimated marginal bid function, by school type

\begin{tabular}{|c|c|c|c|c|c|c|c|c|}
\hline & Primary school & & $\begin{array}{l}\text { EMI-linked } \\
\text { primary } \\
\text { school }\end{array}$ & & $\begin{array}{c}\text { Private primary } \\
\text { school }\end{array}$ & & $\begin{array}{c}\text { Private EMI- } \\
\text { linked primary } \\
\text { school }\end{array}$ & \\
\hline Distance to primary school & $\begin{array}{l}-0.04 \\
(0.01)\end{array}$ & $* *$ & & & & & & \\
\hline $\begin{array}{l}\text { Distance to EMI-linked } \\
\text { primary school }\end{array}$ & & & $\begin{array}{l}-0.01 \\
(0.00)\end{array}$ & $* *$ & & & & \\
\hline $\begin{array}{l}\text { Distance to private primary } \\
\text { school }\end{array}$ & & & & & $\begin{array}{l}-0.06 \\
(0.00)\end{array}$ & $* *$ & & \\
\hline $\begin{array}{l}\text { Distance to private EMI-linked } \\
\text { primary school }\end{array}$ & & & & & & & $\begin{array}{l}-0.04 \\
(0.02)\end{array}$ & $* *$ \\
\hline $\begin{array}{l}\text { Ln (average non-housing } \\
\text { expenditure) }\end{array}$ & $\begin{array}{l}-2.18 \\
(0.38)\end{array}$ & $* *$ & $\begin{array}{l}-2.26 \\
(8.28)\end{array}$ & $*$ & $\begin{array}{c}5.58 \\
(6.11)\end{array}$ & $*$ & $\begin{array}{c}3.66 \\
(1.29)\end{array}$ & $* *$ \\
\hline $\begin{array}{l}\text { Ln (average household } \\
\text { income) }\end{array}$ & $\begin{array}{c}0.02 \\
(0.03)\end{array}$ & & $\begin{array}{c}0.09 \\
(0.08)\end{array}$ & & $\begin{array}{c}0.29 \\
(0.07)\end{array}$ & $* *$ & $\begin{array}{c}0.25 \\
(0.04)\end{array}$ & $* *$ \\
\hline Average household size & $\begin{array}{c}1.84 \\
(0.21)\end{array}$ & $* *$ & $\begin{array}{c}0.76 \\
(6.02)\end{array}$ & & $\begin{array}{l}-0.39 \\
(0.05)\end{array}$ & $* *$ & $\begin{array}{l}-0.23 \\
(0.09)\end{array}$ & $* *$ \\
\hline$\left(\right.$ Average household size) ${ }^{2}$ & $\begin{array}{l}-0.02 \\
(0.03)\end{array}$ & & $\begin{array}{l}-0.20 \\
(0.73)\end{array}$ & & $\begin{array}{c}0.04 \\
(0.01)\end{array}$ & $* *$ & $\begin{array}{c}0.03 \\
(0.10)\end{array}$ & \\
\hline $\begin{array}{l}\text { Average age of household } \\
\text { head }\end{array}$ & $\begin{array}{l}-0.82 \\
(0.12)\end{array}$ & $* *$ & $\begin{array}{l}-0.60 \\
(0.04)\end{array}$ & $* *$ & $\begin{array}{c}0.31 \\
(0.16)\end{array}$ & & $\begin{array}{c}0.35 \\
(0.62)\end{array}$ & \\
\hline $\begin{array}{l}\text { (Average age of household } \\
\text { head) }\end{array}$ & $\begin{array}{c}0.01 \\
(0.00)\end{array}$ & $* *$ & $\begin{array}{c}0.01 \\
(0.00)\end{array}$ & $* *$ & $\begin{array}{c}0.00 \\
(0.00)\end{array}$ & $* *$ & $\begin{array}{l}-0.01 \\
(0.01)\end{array}$ & \\
\hline $\begin{array}{l}\text { Average household size x year } \\
2001\end{array}$ & $\begin{array}{l}-1.05 \\
(0.07)\end{array}$ & $* *$ & $\begin{array}{l}-0.63 \\
(0.24)\end{array}$ & $* *$ & $\begin{array}{l}-0.20 \\
(0.15)\end{array}$ & & $\begin{array}{l}-0.60 \\
(0.44)\end{array}$ & \\
\hline $\begin{array}{l}(\text { Average household size) })^{2} \mathrm{x} \\
\text { year } 2001\end{array}$ & $\begin{array}{c}0.03 \\
(0.02)\end{array}$ & & $\begin{array}{c}0.21 \\
(0.13)\end{array}$ & & $\begin{array}{c}0.02 \\
(0.12)\end{array}$ & & $\begin{array}{c}0.05 \\
(0.03)\end{array}$ & \\
\hline $\begin{array}{l}\text { Average age of household } \\
\text { head x year } 2001\end{array}$ & $\begin{array}{c}0.71 \\
(0.37)\end{array}$ & & $\begin{array}{l}-0.17 \\
(0.15)\end{array}$ & & $\begin{array}{l}-0.60 \\
(0.33)\end{array}$ & & $\begin{array}{l}-0.05 \\
(0.12)\end{array}$ & \\
\hline $\begin{array}{l}\text { (Average age of household } \\
\text { head) })^{2} \text { x year } 2001\end{array}$ & $\begin{array}{c}0.13 \\
(0.12)\end{array}$ & & $\begin{array}{c}0.09 \\
(0.04)\end{array}$ & $* *$ & $\begin{array}{c}0.04 \\
(0.05)\end{array}$ & & $\begin{array}{l}-0.04 \\
(0.09)\end{array}$ & \\
\hline Year 2001 & $\begin{array}{l}-2.24 \\
(1.22)\end{array}$ & $*$ & $\begin{array}{c}0.03 \\
(0.02)\end{array}$ & & $\begin{array}{c}0.28 \\
(0.08)\end{array}$ & $* *$ & $\begin{array}{c}2.11 \\
(1.04)\end{array}$ & $* *$ \\
\hline Intercept & $\begin{array}{c}2.76 \\
(2.79)\end{array}$ & & $\begin{array}{c}0.99 \\
(0.86)\end{array}$ & & $\begin{array}{c}1.01 \\
(5.55)\end{array}$ & & $\begin{array}{c}2.82 \\
(1.61)\end{array}$ & \\
\hline $\begin{array}{l}R \text { squared } \\
N\end{array}$ & $\begin{array}{c}0.26 \\
7,000\end{array}$ & & $\begin{array}{c}0.29 \\
1,725\end{array}$ & & $\begin{array}{c}0.27 \\
1,815\end{array}$ & & $\begin{array}{l}0.37 \\
812\end{array}$ & \\
\hline
\end{tabular}

Notes: The dependent variable is the log of the marginal bid for each 100 metres closer to the nearest primary school. Distance to school and non-housing expenditures are endogenous; they are instrumented by the district dummy and its interaction with the demand shifters. Variables for the demand shifters are obtained from the census profiles of STPUs and are spatial averages. Standard errors are in parentheses. Single asterisks identify significance at the 10-percent level, double asterisks at the 5-percent level. Calculations by the authors. 
Figure 1 The study area

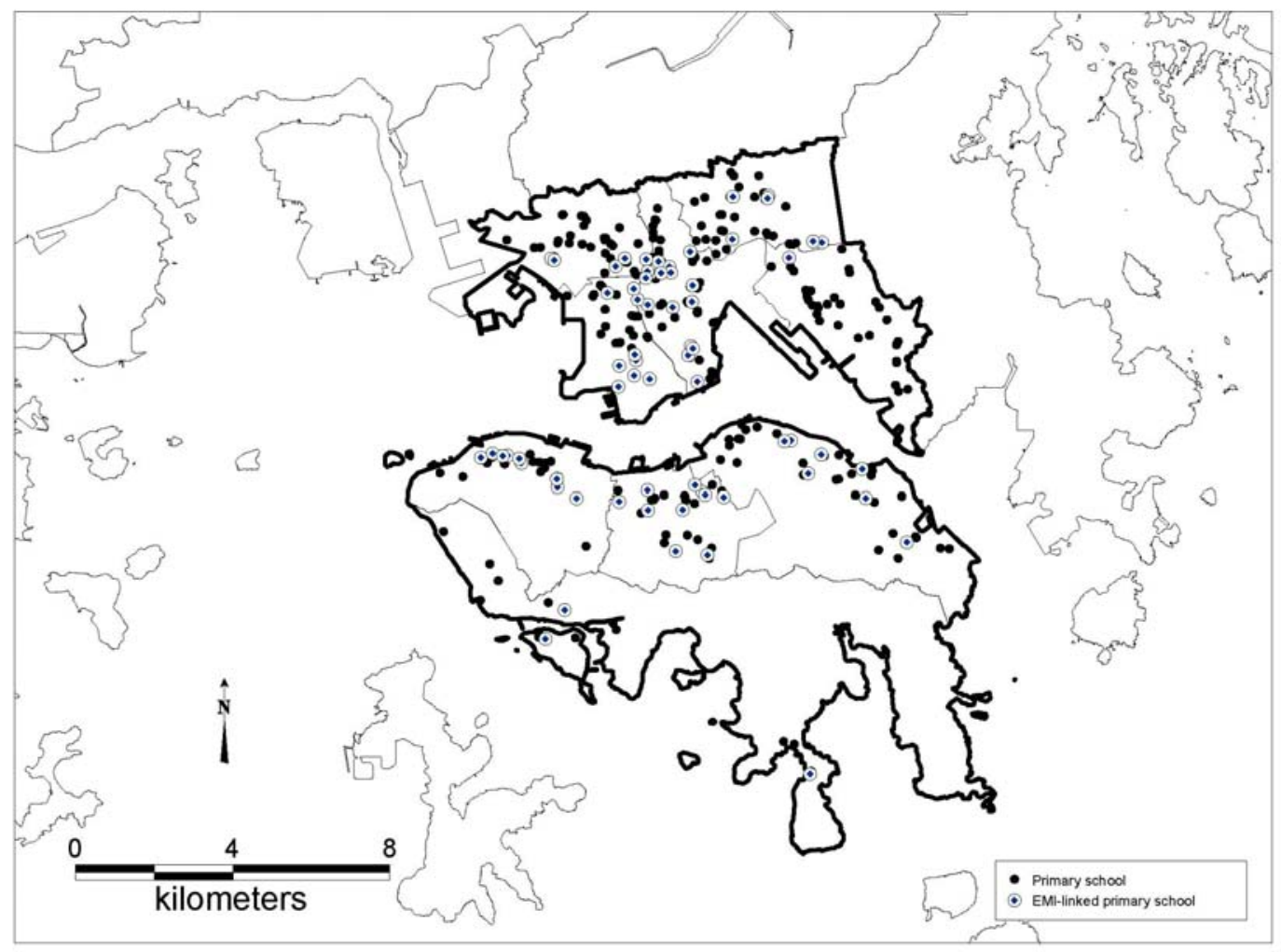

Notes: Boundary files provided by MapInfo. The remaining areas form the New Territories in Hong Kong. Each black dot represents a primary school and a circled dot represents an EMI-linked primary school. Map prepared by the authors. 
Figure 2 Hong Kong house price index, 1995-2008

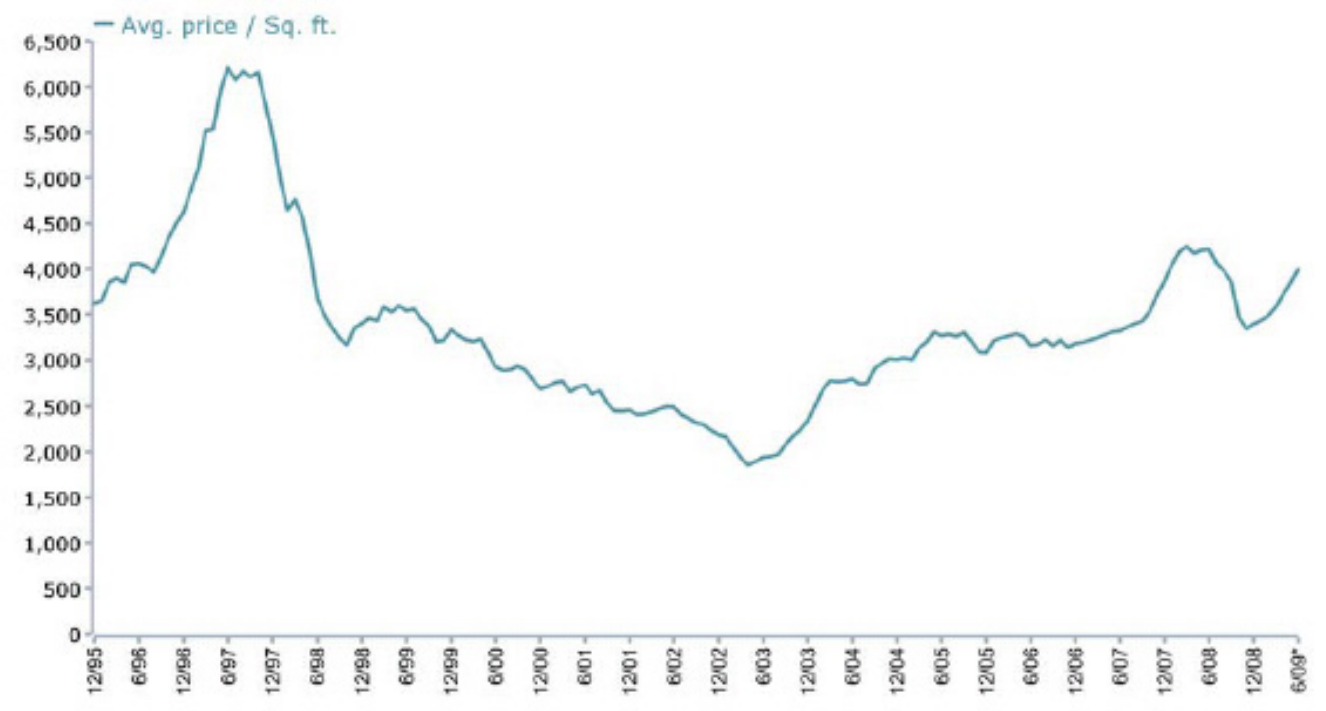

Source: Midland Realty Hong Kong, 2009 
Appendix 1 Secondary school allocation in Hong Kong

The Hong Kong government provides children with nine years of free, compulsory

education covering grades one to nine. Upon graduation from primary 6 (grade 6), pupils

were allocated to public or aided secondary schools for another three years of compulsory education, through either discretionary placement or central allocation. Neither allocation scheme applies to pupils seeking private secondary education.

Less than 13 percent of all grade 6 pupils were allocated by discretionary placement successfully. Under the discretionary placement scheme, public and aided secondary schools were given an annual quota -10 percent of total admissions - for accepting grade 6 pupils based on schools’ discretionary assessment criteria. ${ }^{36,37}$ Grade 6 pupils could apply to any discretionary placement regardless of the school district.

Close to 85 percent of all grade 6 pupils were allocated to secondary schools through the central allocation scheme. In accordance with this scheme, allocation was determined by five elements: the school district in which the primary school was located, the parental choice of secondary school, three internal assessments of the pupil's school performance, the primary school's overall performance on a public aptitude test, and a computer-generated random number for each pupil.

A key element of the central allocation system was the school district in which the primary school was located. The school district defined the types and quality of secondary schools available for parents to choose from. Each year, parents of grade 6 pupils were given a list of secondary schools within the school district and were asked to rank them.

\footnotetext{
${ }^{36}$ In 2001 the quota was changed from 10 percent to 20 percent.

${ }^{37}$ Prior to 2001, secondary schools could use both written tests and interviews to assess pupils applying for discretionary placement. As of 2001, only interviews were allowed.
} 
The quality of primary schools was critical to determining secondary-school allocation, because the overall school performance would be used to rescale any individual pupil’s assessment score. Each pupil was assessed internally three times: at the end of grade 5, mid-year in grade 6 and at the end of grade 6. Pupils would then be ranked within their own school, based on the results of the internal assessment. Meanwhile all participating grade 6 pupils would write a public aptitude test. ${ }^{38}$ The overall performance of all pupils in a school in this test would be used to rank all participating primary schools in Hong Kong; the school ranking formed the basis for rescaling the individual pupil's internal assessment results. In this way, all grade 6 pupils would be divided into five groups, adjusted by the school's overall relative standing. Each group, or band, would comprise 20 percent of all pupils within a school district, with band one pupils scoring in the top 20th percentile of the rescaled internal assessments. $^{39}$ Because of the critical role of primary schools in the rescaling process, parents were motivated to enrol their child in a quality primary school in order to secure a placement in an English secondary school.

The rescaled assessment score, together with a computer-generated number, would determine pupils' order of allocation. Band one pupils would be the first to choose their ideal school, followed by lower-band pupils. Pupils within the same band were seen as equal in terms of academic aptitude; therefore, to give pupils in the same band a fair chance at choosing their ideal school, each pupil would be given a random number to determine the order of allocation.

\footnotetext{
${ }^{38}$ The public aptitude test was abolished in 2001; the policy goal was to eventually use internal assessment results only. As a transition, in 2001 the scaling factor for schools was the average school performance in the aptitude test over the preceding three years.

${ }^{39}$ In 2001 the number of bands was reduced to three. The rationale for this policy change was that a smaller number of bands might lead to increased diversity within schools.
} 
Appendix 2 Hedonic regression results, 1996 and 2001, by 2SLS

\section{Variables}

Primary school

EMI-linked primary

Non-government-related primary school

Non-government-related EMI-linked primary school

Days on market

Age

$(\text { Age })^{2}$

Floor

8th Floor

4th Floor

Percent public housing in neighbourhood

All-girls/All-boys primary school

Whole-day primary school

Chi Fu Fa Yuen

Taikoo

Laguna

Whampoa Garden

Telford Garden

Sceneway

Amoy Garden

Parc Oasis

Mei Foo Sun Chun

South Horizon

Heng Fa Chuen

Kornhill
1996 sample

0.0322

(0.0030)

0.0007

$(0.0004)$

0.0024

(0.0003)

0.0001

(0.0006)

$-0.0844$

(0.0068)

$-0.0359$

(0.0023)

0.0004

$(0.0001)$

0.0050

(0.0006)

0.0495

(0.0166)

$-0.0826$

(0.0171)

$-1.0526$

(0.1449)

0.0701

(0.0196)

$-0.0912$

(0.0113)

0.0674

(0.0519)

0.4422

(0.0327)

$-0.2513$

(0.0379)

0.2381

(0.0239)

0.3240

(0.0409)

0.1894

(0.0440)

0.1152

(0.0360)

0.4530

(0.0529)

$-0.1340$

(0.0302)

$-0.0992$

(0.0351)

0.0543

$(0.0422)$

0.5626

(0.0442)
2001 sample

** 0.0282

(0.0040)

* $\quad 0.0002$

(0.0004)

** $0.0026 \quad * *$

(0.0004)

$0.0017 \quad * *$

(0.0007)

** $\quad-0.0518 \quad * *$

(0.0098)

** $\quad-0.0282$

(0.0025)

** $\quad 0.0002$

(0.0001)

** $\quad 0.0074$

(0.0007)

** 0.0310 *

(0.0193)

** $\quad-0.0204$

(0.0189)

** -1.0534 **

(0.0891)

** $\quad 0.0893 \quad * *$

(0.0239)

** $\quad-0.0880$

(0.0134)

0.1528

(0.0663)

** $\quad 0.2297$

(0.0387)

** $\quad-0.1653$

(0.0433)

** $\quad 0.0533$

(0.0303)

** 0.3966

(0.0550)

** $\quad 0.0345$

(0.0502)

** $\quad-0.0896$

(0.0402)

** $\quad 0.4139$ **

(0.0662)

** $\quad-0.0587$ *

(0.0351)

** $\quad-0.0147$

(0.0399)

0.1584

(0.0508)

** $\quad 0.2172$

(0.0498) 
Proximity to CBD

Proximity to nearest MTR station

0.0056

$(0.0028)$

0.0158

$(0.0042)$

8.3807

$(0.2028)$

$R$ squared

N

Notes: Price data are acquired from one of the largest local realtors in Hong Kong.

School data are obtained from individual school Web sites. All addresses are geocoded against the street network file acquired from MapInfo. The dependent variable is the log of the per-square-foot sell price of a flat. All distances are measured in 100 metres and are subtracted from an arbitrary constant of five kilometres. They are interpreted as each 100 metres closer to the nearest school, an MTR station or the CBD. Days on market is endogenous and is instrumented by the season in which the flat is sold. Standard errors are in parentheses. Single asterisks identify significance at the 10-percent level, double asterisks at the 5-percent level. Calculations by the authors. 